\title{
Predictors of Nonadherence to Topical Intraocular Pressure Reduction Medications Among Medicare Members: A Claims-Based Retrospective Cohort Study
}

\author{
Richard Sheer, BA; Suvapun Bunniran, PhD; Claudia Uribe, MD, MHA, PhD;
} Richard G. Fiscella, PharmD, MPH; Vaishali D. Patel, PharmD, MS; and Hitesh S. Chandwani, MBBS, PhD

\begin{abstract}
BACKGROUND: Reported adherence rates with ocular hypotensive medications typically range from $51 \%$ to $56 \%$ over the first year of therapy. As intraocular pressure (IOP) reduction slows the progression of vision loss from glaucoma, early identification of nonadherent members is crucial to effective disease management.

OBJECTIVES: To (a) identify member characteristics and other factors related to nonadherence with topical IOP-lowering medications available in administrative claims data and (b) create a predictive model incorporating these variables.

METHODS: This retrospective cohort study analyzed data from Humana's administrative claims database. The study cohort included members aged 65-89 years enrolled in a Medicare Advantage Prescription Drug plan (MAPD; medical and pharmacy benefits), with $\geq 1$ topical IOP-lowering medication claims between January 2011 and September 2012 and a minimum of 24 months of continuous enrollment-12 months before and 12 months after the initial (index) prescription claim for a topical IOP-lowering medication. Adherence was defined as the proportion of days covered (PDC) with drug supply (calculated from the number of drops per bottle and dose) over the first year after the index prescription. Members with $P D C \geq 0.80$ were considered adherent, while members with $\mathrm{PDC}<0.80$ were considered nonadherent. Multivariable stepwise logistic regression with backward elimination was used to construct a predictive model for the likelihood of nonadherence (PDC < 0.80$)$. The model was developed using 28 input variables-10 variables were retained in the final model.
\end{abstract}

RESULTS: 73,256 MAPD members were included in this study; most (69\%) of these members were continuing topical IOP-lowering medication users. The proportion of patients adherent $(\mathrm{PDC} \geq 0.80)$ to IOP-lowering medications was $51 \%$. The study sample was split, using a 2:1 ratio, into a development sample ( $n=48,840$ members) and a validation sample $(n=24,416$ members). The model performed equally well in the development sample and the validation sample (area under the curve $=0.71$ for development and validation sets), making it appear robust in this Medicare population. In the final predictive model, characteristics increasing the likelihood $(P<0.01)$ of nonadherence to IOP-lowering medication within the MAPD population included index IOP prescription filled through mail order, higher medical costs during the pre-index period, being a new IOP-lowering medication user, and being male. Characteristics that lowered the likelihood of nonadherence included advanced age, higher pharmacy costs during the pre-index period, receiving a low-income subsidy, residing in the South, and a previous diagnosis of open-angle glaucoma or history of glaucoma surgery.

CONCLUSIONS: Nonadherence to topical IOP-lowering medication can be predicted with 10 commonly available demographic, clinical, and treatment-related variables generally available in administrative claims data for an MAPD population. Given that this predictive model was constructed using these generally available data, it could potentially be replicated by other health plans for use in predicting nonadherence to topical
IOP-lowering medications among MAPD plan members. This predictive model can be used to identify members that are likely to be nonadherent in order to target interventions intended to improve ocular hypotensive medication adherence.

J Manag Care Spec Pharm. 2016;22(7):808-17

Copyright $\odot 2016$, Academy of Managed Care Pharmacy. All rights reserved.

\section{What is already known about this subject}

Poor adherence is a common problem among patients treated with topical ocular hypotensive medications.

Examination of adherence to ophthalmic topical intraocular pressure-lowering medications presents a unique challenge for calibration of days supply from prescription claims data.

Days supply calculations using the pharmacy claims-based "days' supply" field can underestimate the actual available medication in the bottle; drop count studies give a more accurate estimate of actual product available in the bottle.

\section{What this study adds}

A predictive model can be developed using medical and pharmacy data generally available in administrative claims to identify potentially nonadherent members to topical intraocular-lowering medications.

Application of drop count methodology to determine days supply of eye drops in claims data allowed for a more accurate calculation.

$\mathrm{M}$ anagement of chronic diseases such as glaucoma, diabetes, and hypertension are problematic for insurance plans from an adherence perspective because patients are typically asymptomatic until later stages of the disease. ${ }^{1}$ When patients are without symptoms, they may not realize the importance of daily adherence to therapy. Glaucoma is a particularly serious problem for the elderly. The prevalence of glaucoma is almost 3 times as high in the population aged over 65 years $(6.1 \%$ vs. $1.9 \%)$, with increasing prevalence as age increases. ${ }^{2}$ In the United States, approximately 1 million people aged over 65 years have vision loss associated with glaucoma, and the prevalence of this disease is expected to increase, since 
the number of people over age 65 is predicted to more than double by $2030 .^{3}$

The 2 types of glaucoma are open-angle and acute angleclosure. ${ }^{4}$ With open-angle glaucoma, symptoms can include peripheral blind spots and tunnel vision and typically progress slowly without indication of vision loss until the disease is very advanced, while acute angle-closure glaucoma can present with severe headache, eye pain, blurred vision, eye redness and may appear suddenly and painfully. ${ }^{4}$ The prevalence of open-angle glaucoma increased from $0.7 \%$ at age 40 to $7.7 \%$ for those over age 80 in the United States. ${ }^{5}$ The only modifiable risk factor for both types of glaucoma is intraocular pressure (IOP). Patients who are noncompliant to topical IOP-lowering medications are more likely to have worse visual outcomes or partial vision loss. ${ }^{6,7}$ Lack of compliance can also lead to an increase in health care costs. ${ }^{8}$

Two thirds of Medicare beneficiaries have multiple chronic conditions, and the prevalence of multiple chronic conditions proliferates with age. ${ }^{9,10}$ These complexities compound the risk for poor outcomes and functional limitations, emphasizing the importance of patient education and the significance of adherence to further prevent disease progression. Studies using a variety of methodologies, including retrospective analyses of pharmacy claims data, patient chart reviews, patient self-reports, and clinical data, reveal that patients are not taking their IOP-lowering medications as intended. ${ }^{1,7,11-15}$ In fact, adherence with ocular hypotensive medications typically ranges from $51 \%$ to $56 \%$ over the first year of therapy. ${ }^{1}$ In a systematic review by Reardon et al. (2011), 1 study based on prescription records found that only $56 \%$ of the days in the first year of therapy could be dosed with the medication supply obtained by patients in a 1-year time period. ${ }^{1}$

Studies have examined predictors of adherence to IOPlowering medications using a variety of measures. ${ }^{11,14,16}$ Chang et al. (2013) found predictors of nonadherence to prostaglandins to be younger age, black race, worse general health status, shorter duration of glaucoma medication therapy, lower selfreported adherence, and admitting to not following doctors' orders. ${ }^{14}$ However, this study required data collection from patients, including an electronic cap monitoring system for adherence monitoring, was limited to prostaglandins, and additional survey measures were collected and included as predictors. In a study using claims data and a drop count methodology, factors associated with nonadherence to topical glaucoma medications included the use of glaucoma medications requiring 2 or more administrations per day and the presence of other medications in the patients' drug regimens. ${ }^{11}$ However, this study was limited to the New Jersey Medicaid population and treatment patterns may differ and not be generalizable.

The difficulty of identifying nonadherent patients based on demographic and clinical characteristics has been demonstrated by previous studies, which have also shown that the use of automated prescription data to identify noncompliant patients is feasible only in large managed health care insurance programs where data are collected routinely for administrative purposes. ${ }^{12,16}$ There is little empirical evidence to identify members who are likely to be nonadherent to topical IOPlowering medications that can be used by clinicians to help manage members on IOP-lowering therapy. While previous studies have examined predictors of nonadherence in topical glaucoma therapies, this study examines variables common to administrative claims, such as gender, age, geographic location, and medical history. These variables can be easily ascertained by clinicians and replicated by other health plans, since the model in this study was developed using a large U.S. managed care database. We report the development of a predictive model that encompasses these variables to identify potentially nonadherent members. This model can help physicians and managed care plans better identify patients who could benefit from greater support for optimal therapy.

The objectives of this study were to (a) identify member characteristics and other factors related to nonadherence with topical IOP-lowering medications available in administrative claims data and (b) create a predictive model incorporating these variables.

\section{Methods}

\section{Data Source}

A retrospective study was conducted using the Humana Research Database. This database contains integrated medical claims, pharmacy claims, and enrollment data, representing over 20 million current and former Humana members enrolled in commercial, Medicare Advantage Prescription Drug (MAPD; medical and pharmacy benefits), and prescription drug plans. For this study, only the MAPD population was examined. The full study period was from January 1, 2010, through September 30,2013 . The finalized protocol was approved by an independent institutional review board.

\section{Study Population}

The study population consisted of MAPD members aged 65-89 years who filled at least 1 prescription for an IOP-lowering medication between January 1, 2011, and September 30, 2012; the index date was defined as the first prescription for an IOPlowering medication during this time frame. IOP-lowering medications included prostaglandin analogs, ophthalmic beta blockers, alpha agonists, carbonic anhydrase inhibitors, fixed ophthalmic combination products, and miotics (Table 1). Eligible members were required to have 24 months of continuous enrollment, which included 12 months before and 12 months after the index date. Members with at least 1 claim for a long-term care facility, including assisted living, skilled nursing facility, nursing home, or hospice at any time during the 24-month observation period, were excluded. 


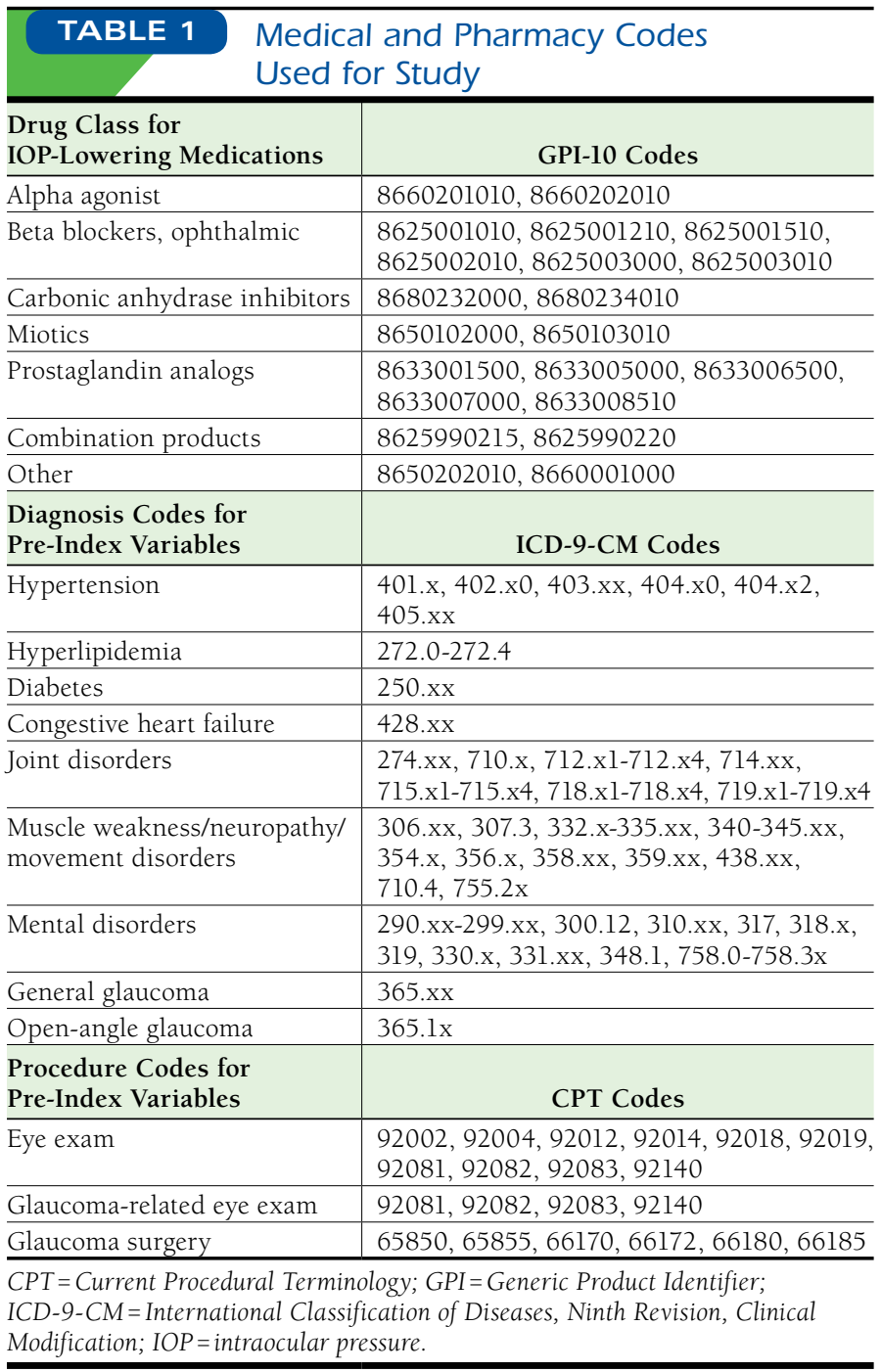

\section{Study Variables}

Baseline demographics on the index date were examined and included age, gender, race, and geographic region, as well as plan type (e.g., health maintenance organization and preferred provider organization) and receipt of a low-income subsidy. Baseline clinical characteristics were assessed during the 12-month pre-index period. These characteristics included comorbidities such as hypertension, hyperlipidemia, diabetes, congestive heart failure, joint disorders, muscle weakness/ movement disorders (Parkinson's disease, amyotrophic lateral sclerosis, muscular dystrophy, epilepsy, cerebral palsy, multiple sclerosis, and peripheral neuropathies), and mental disorders (dementia, psychoses, Alzheimer's disease, brain damage, and drug or alcohol dependence), as well as glaucoma-related measures including a glaucoma diagnosis or an open-angle glaucoma diagnosis by an ophthalmologist, a glaucoma-related eye exam, or glaucoma surgery (see Table 1 for diagnosis and procedure codes). Pharmacy-based measures commonly assessed in adherence analyses included whether a patient was a new or continuing user of IOP-lowering medications (alpha agonists, ophthalmic beta blockers, carbonic anhydrase inhibitors, miotics, prostaglandin analogs, and combination products; all members were classified as new users except those whose index date was in 2011 and had a claim for IOPlowering medications within 12 months before the index date); the distribution channel of the index script (whether the prescription was retail or mail order); the source of the index prescription (e.g., written, electronic, phone, and fax); the formulary tier of the index prescription; the specialty and gender of the prescribing physician of the index prescription; Rx-Risk-V score (a prescription claims-based composite risk score based on the number of unique medication fills using the Generic Product Identifier [GPI] ${ }^{17-20}$; the number of unique medications as measured by GPI drug group; and the number of pharmacies visited for any medication fill. Total cost (health plan cost plus out-of-pocket cost) was also evaluated for medical and pharmacy claims during the baseline period and was adjusted to 2012 dollars. Cost variables were log-transformed to control for high-end outliers. ${ }^{21,22}$

\section{Days Supply}

To account for the medication being dispensed in liquid form, days supply was defined using the drop count methodology, since claims-based estimates of days supply for eye drops are known to be inaccurate. ${ }^{23}$ The days supply in pharmacy claims is often reported as a fixed 30 or 90 days supply and can underestimate the actual amount of liquid available in the containers, which are typically overfilled to a greater or lesser degree. .1,23,24 $^{2}$ An adjusted days supply specific to each medication and dose was determined using the drop-count approach, a methodology applied by several published studies. ${ }^{11,23-25}$ These dropcount studies determined the actual volume of drug solution contained in commer $\urcorner$ cially available bottles and the number of drops dispensed from each bottle, generalizing per class of medication and bottle size..$^{11,24}$ Using data generated from the use of these methods, adherence for each medication was determined using adjusted days supply and the proportion of days covered (PDC) method.

\section{Adherence and PDC}

Adherence was measured over the 12-month follow-up period, including the index date, using PDC. ${ }^{26}$ Members were defined as nonadherent if they filled <292 days of an IOP-lowering medication in the year after the index date, which was equivalent to $\mathrm{PDC}<0.80$. The a priori definition of the adherence cutpoint was $0.80 .1,26,27$

PDC was calculated using the following formula (switching IOP-lowering medications was allowed): PDC $=$ Total number of 


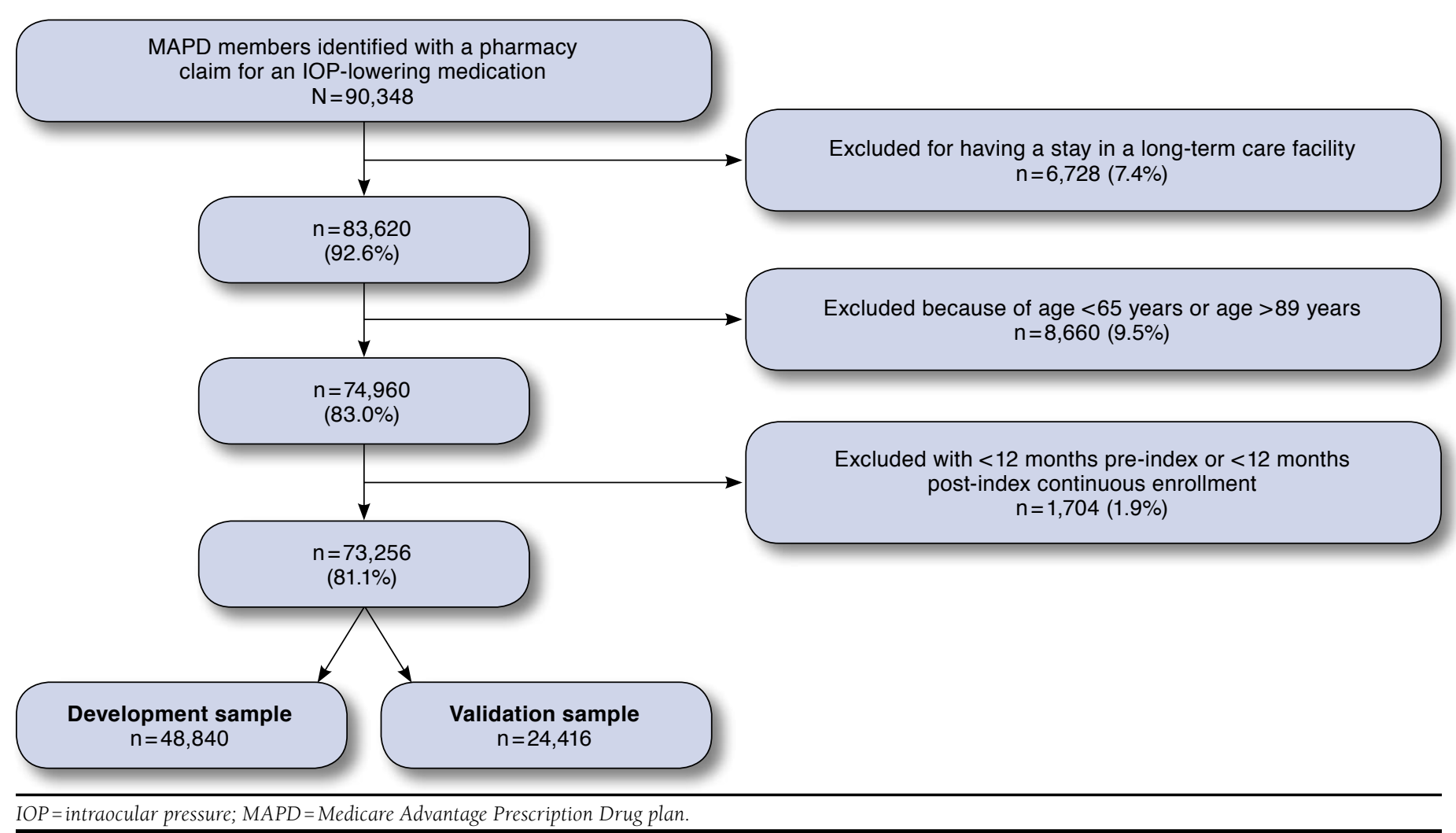

days for which medication was available to the member during the 365-day assessment period divided by 365 days. For members with overlapping prescriptions (i.e., having a prescription filled before the days supply of the previous prescription ran out), the PDC method adjusts the start date of the new prescription to begin the day after the previous script's days supply ended.

\section{Statistical Analysis and Model Development}

Descriptive statistics were reported for baseline demographics and clinical measures. Multivariable logistic regression was used to build a predictive model to identify the members with the highest probability of being nonadherent to IOP-lowering medications. The model was created on a development dataset that was composed of two thirds of the eligible study population. All variables assessed during the baseline descriptive analysis were incorporated into the initial model. These variables included member age, gender, race, and geographic region; plan type; low-income subsidy; Rx-Risk-V composite risk score; presence of hypertension, hyperlipidemia, diabetes, congestive heart failure, joint disorders, muscle weakness/ movement disorders, mental disorders, or glaucoma; glaucoma surgery, a glaucoma-related eye exam, or open-angle glaucoma diagnosed by an ophthalmologist; number of physicians seen; number of pharmacies used; new versus continuing users of IOP-lowering medications; source of prescription, mail order versus retail, formulary tier, prescriber gender, and prescriber specialty for the index IOP-lowering prescriptions; and preindex medical and pharmacy costs (see Appendix, available in online article). The goal was to build a parsimonious model that would be applicable across managed care data sources. To achieve this type of model, principal components analysis was used to reduce the number of input variables. ${ }^{28}$ The final predictive model was created using backwards-selection logistic regression with a significance level of 0.01 . The model was validated on a validation sample consisting of the remaining one third of the eligible population that was not used for model development. Final model results were reported as odds ratios (OR) and 95\% confidence intervals (CI) for predictor variables and c-statistics, as well as performance measures such as sensitivity, specificity, and positive and negative predictive value at varying probability thresholds.

\section{Results}

\section{Attrition and Baseline Characteristics}

A total of 73,256 MAPD members met all inclusion criteria for the study (Figure 1). The mean age was 76 years ( \pm 6.3 years); 


\section{Predictors of Nonadherence to Topical Intraocular Pressure Reduction Medications Among Medicare Members: A Claims-Based Retrospective Cohort Study}

\section{TABLE 2 Baseline (Pre-Index) Patient Characteristics by Cohort}

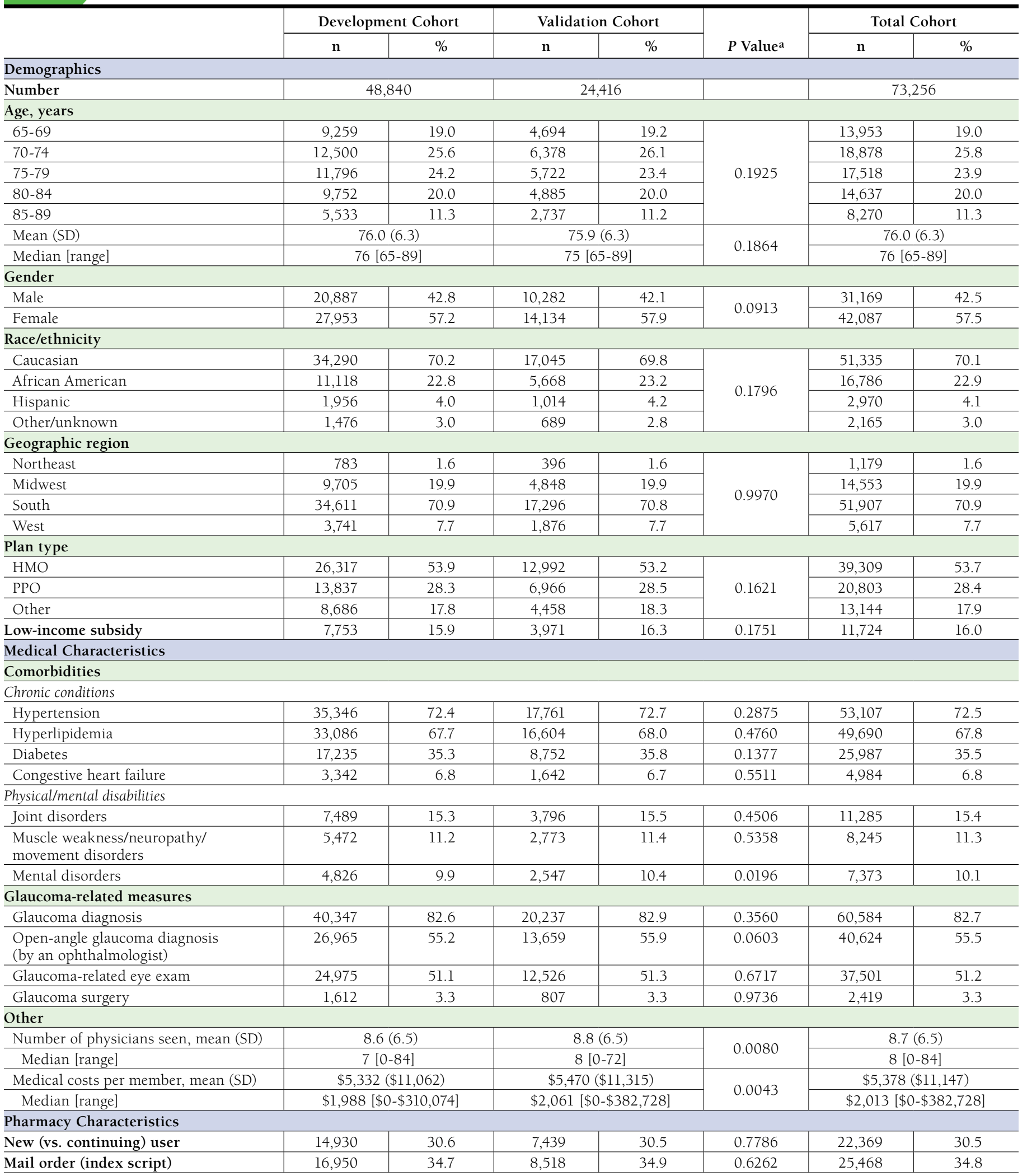




\section{Predictors of Nonadherence to Topical Intraocular Pressure Reduction Medications Among Medicare Members: A Claims-Based Retrospective Cohort Study}

TABLE 2 Baseline (Pre-Index) Patient Characteristics by Cohort (continued)

\begin{tabular}{|c|c|c|c|c|c|c|c|}
\hline & \multicolumn{2}{|c|}{ Development Cohort } & \multicolumn{2}{|c|}{ Validation Cohort } & \multirow[b]{2}{*}{$P$ Value ${ }^{a}$} & \multicolumn{2}{|c|}{ Total Cohort } \\
\hline & n & $\%$ & $\mathbf{n}$ & $\%$ & & n & $\%$ \\
\hline \multicolumn{8}{|l|}{ Pharmacy Characteristics } \\
\hline \multicolumn{8}{|l|}{ Source of index prescription } \\
\hline Written & 23,747 & 48.6 & 11,898 & 48.7 & \multirow{5}{*}{0.6175} & 35,645 & 48.7 \\
\hline Electronic & 11,807 & 24.2 & 5,789 & 23.7 & & 17,596 & 24.0 \\
\hline Phone & 5,012 & 10.3 & 2,516 & 10.3 & & 7,528 & 10.3 \\
\hline Fax & 7,912 & 16.2 & 4,012 & 16.4 & & 11,924 & 16.3 \\
\hline Other & 362 & 0.7 & 201 & 0.8 & & 563 & 0.8 \\
\hline \multicolumn{8}{|l|}{ Formulary tier (index prescription) } \\
\hline Tier 1 & 6,581 & 13.5 & 3,297 & 13.5 & \multirow{3}{*}{0.9860} & 9,878 & 13.5 \\
\hline Tier 2 & 34,222 & 70.1 & 17,120 & 70.1 & & 51,342 & 70.1 \\
\hline Other & 8,037 & 16.5 & 3,999 & 16.4 & & 12,036 & 16.4 \\
\hline \multicolumn{8}{|l|}{ Prescriber specialty (index prescription) } \\
\hline Ophthalmologist & 31,291 & 64.1 & 15,621 & 64.0 & \multirow{4}{*}{0.9834} & 46,912 & 64.0 \\
\hline Optometrist & 8,238 & 16.9 & 4,133 & 16.9 & & 12,371 & 16.9 \\
\hline Family practitioner/internal medicine & 2,059 & 4.2 & 1,020 & 4.2 & & 3,079 & 4.2 \\
\hline Other/unknown & 7,252 & 14.8 & 3,642 & 14.9 & & 10,894 & 14.9 \\
\hline \multicolumn{8}{|l|}{ Prescriber gender (index prescription) } \\
\hline Male & 31,947 & 65.4 & 15,944 & 65.3 & \multirow{3}{*}{0.4559} & 47,891 & 65.4 \\
\hline Female & 7,096 & 14.5 & 3,491 & 14.3 & & 10,587 & 14.5 \\
\hline Unknown & 9,797 & 20.1 & 4,981 & 20.4 & & 14,778 & 20.2 \\
\hline Rx-Risk-V score, mean (SD) & \multicolumn{2}{|c|}{$6.0(2.9)$} & \multicolumn{2}{|c|}{$6.0(2.9)$} & \multirow{2}{*}{0.0718} & \multicolumn{2}{|c|}{$6.0(2.9)$} \\
\hline Median [range] & \multicolumn{2}{|c|}{$6[1-20]$} & \multicolumn{2}{|c|}{6 [1-20] } & & \multicolumn{2}{|c|}{6 [1-20] } \\
\hline Number of pharmacies visited, mean (SD) & \multicolumn{2}{|c|}{$2.1(1.1)$} & \multicolumn{2}{|c|}{$2.1(1.1)$} & \multirow{2}{*}{0.5577} & \multicolumn{2}{|c|}{$2.1(1.1)$} \\
\hline Median [range] & \multicolumn{2}{|c|}{$2[1-25]$} & \multicolumn{2}{|c|}{$2[1-12]$} & & \multicolumn{2}{|c|}{$2[1-25]$} \\
\hline Pharmacy costs, mean (SD) & \multicolumn{2}{|c|}{$\$ 2,439(\$ 3,126)$} & \multicolumn{2}{|c|}{$\$ 2,460(\$ 3,165)$} & \multirow{2}{*}{0.1736} & \multicolumn{2}{|c|}{$\$ 2,446(\$ 3,139)$} \\
\hline Median [range] & $\$ 1,809$ & $0,243]$ & $\$ 1,82 \varepsilon$ & $1,051]$ & & $\$ 1,810$ & ,243] \\
\hline
\end{tabular}

$57.5 \%$ were female; and $70.1 \%$ were white (Table 2). The majority of members resided in the South (70.9\%), with an additional 19.9\% in the Midwest. Sixteen percent of members received a lowincome subsidy, and 10.9\% were Medicare-Medicaid dual eligible.

Most members had at least 1 of the reported chronic illnesses (Table 2). Hypertension (72.5\%) and hyperlipidemia (67.8\%) were most common, and approximately one third (35.5\%) of the members had type 2 diabetes. Physical and mental disabilities were not as prevalent: joint disorders were found in $15.4 \%$ of members, followed by muscle and movement disorders (11.3\%) and mental disorders (10.1\%). The vast majority of patients were diagnosed with glaucoma (82.7\%), although open-angle glaucoma was less common (67.8\%), with more than half (55.5\%) of the members diagnosed or treated for open-angle glaucoma by an ophthalmologist. Eye exams were performed on over $80 \%$ of patients.

More than 30\% of patients were new users of IOP-lowering medications. Patients were taking 8 total medications (not specific to glaucoma), on average $( \pm 4)$, and had them filled at an average of 2 different pharmacies $( \pm 1)$. The index prescription was filled by mail order for $34.8 \%$ of patients, with a large majority (76.8\%) receiving 43-59 days of medication for the index script using the drop count methodology. Total pharmacy costs per member during the 12-month pre-index period were $\$ 2,446( \pm \$ 3,139)$; total medical costs were higher $(\$ 5,378$ $\pm \$ 11,147)$.

\section{Adherence and Predictors of Nonadherence}

The mean medication adherence was PDC $=0.72( \pm 0.29)$ and the median was PDC $=0.81$ (Table 3). A PDC threshold of 0.80 was used to classify patients as adherent or nonadherent. Just over half of the study population (50.9\%) was adherent using this definition (Table 3). Adherence varied by drug class. Users of carbonic anhydrase inhibitors (53\%) and prostaglandin analogs (52\%) had the highest adherence; users of miotics (32\%) and alpha agonists (39\%) had the lowest adherence. Adherence was higher among continuing users (59\%) than among new users (33\%; Table 3).

The sample used to develop the model included 48,840 patients (the validation sample had 24,416 patients). The cohorts were similar in almost all baseline patient characteristics for the development and validation cohorts (Table 2). 


\begin{tabular}{|c|c|c|}
\hline $\begin{array}{l}\text { Adheren } \\
\text { (Proporti }\end{array}$ & \multicolumn{2}{|c|}{$\begin{array}{l}\text { Adherence to IOP-Lowering Medications } \\
\text { (Proportion of Days Covered) }\end{array}$} \\
\hline Number of users & \multicolumn{2}{|c|}{73,256} \\
\hline Mean PDC (SD) & \multicolumn{2}{|c|}{$0.72(0.29)$} \\
\hline Median PDC [IQR] & \multicolumn{2}{|c|}{$0.81[0.49-1.00]$} \\
\hline Percent Adherence (PDC) & Number of Users & Percentage \\
\hline$\geq 0.80$ & 37,261 & 50.9 \\
\hline $0.60-0.79$ & 11,526 & 15.7 \\
\hline $0.40-0.59$ & 10,769 & 14.7 \\
\hline $0.20-0.39$ & 9,350 & 12.8 \\
\hline$<0.20$ & 4,350 & 5.9 \\
\hline PDC by Class & Number of Users & Percent Adherent \\
\hline Alpha agonists & 4,604 & 38.9 \\
\hline Beta blockers, ophthalmic & 16,218 & 45.5 \\
\hline Carbonic anhydrase inhibitors & 1,982 & 53.4 \\
\hline Combination drugs & 3,156 & 41.1 \\
\hline Miotics & 539 & 32.3 \\
\hline Multiple products & 8,220 & 65.2 \\
\hline Prostaglandin analogs & 38,535 & 52.4 \\
\hline Other & 2 & 100.0 \\
\hline PDC by User & Number of Users & Percent Adherent \\
\hline New user & 22,369 & 33.4 \\
\hline Continuing user & 50,887 & 58.5 \\
\hline
\end{tabular}

The validation cohort had a greater percentage of patients with mental disorders $(10.4 \%$ vs. $9.9 \%, P=0.0196)$; saw a greater number of physicians in the 12 -month pre-index period ( $8.8 \mathrm{vs}$. $8.6, P=0.008$ ); and had more medical costs ( $\$ 5,470$ vs. $\$ 5,332$, $P=0.0043$ ). The 28 variables previously mentioned (see also the Appendix) were included in the initial regression model. Principal components analysis was used to combine redundant dimensions and reduce the model to 19 variables. Stepwise logistic regression with backward elimination retained 10 of the 19 variables as significant predictors $(P<0.01)$.

Table 4 lists the parameter estimates for the final model variables. The use of mail order for the index script $(\mathrm{OR}=2.68$; 95\% $\mathrm{CI}=2.57-2.79)$ and being a new user $(\mathrm{OR}=2.48 ; 95 \%$ $\mathrm{CI}=2.37-2.60)$ were the most significant predictors of nonadherence, followed by being male $(\mathrm{OR}=1.10 ; 95 \% \mathrm{CI}=1.06-1.15)$ and pre-index medical costs $(\mathrm{OR}=1.09 ; 95 \% \mathrm{CI}=1.08-1.10)$. A diagnosis of open-angle glaucoma by an ophthalmologist was most strongly associated with reduced likelihood of nonadherence $(\mathrm{OR}=0.69 ; 95 \% \mathrm{CI}=0.66-0.72)$ followed by residence in the southern region of the United States (OR $=0.73 ; 95 \%$ $\mathrm{CI}=0.70-0.76)$ and having had glaucoma surgery during the pre-index period $(\mathrm{OR}=0.76 ; 95 \% \mathrm{CI}=0.68-0.85)$.

The model had an accuracy (efficiency) rate of $66.1 \%$ at the cutoff level of $>0.50$, indicating that when targeted patients have a predicted probability of nonadherence of $50 \%$ or higher, approximately two thirds are correctly classified as being true

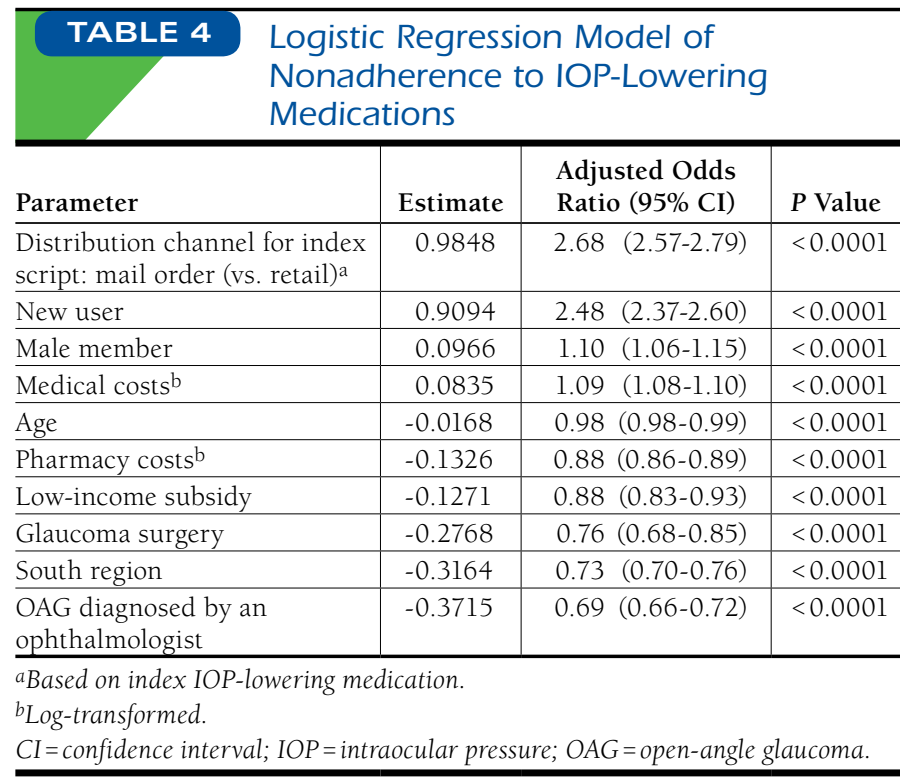

positives or true negatives. A sensitivity analysis was performed, and at a cutoff of 0.6 (i.e., those that are at least $60 \%$ likely to be nonadherent), the accuracy was $63.3 \%$; at a cutoff of 0.7 , the accuracy was $58.1 \%$. This cutoff was chosen because of the relatively high proportion of the study population that was nonadherent (49\%). Another consideration was a desire for a lower rate of false negatives so as to identify as many potential nonadherent patients as possible for targeted intervention. The c-statistic for the model was 0.710; when applied to the validation sample, it performed equally well (0.705). The c-statistic, or area under the curve (AUC), was defined as the percent likelihood that a nonadherent member chosen at random had a higher predicted probability of being nonadherent (based on the results of the model) than an adherent member chosen at random. An ROC (receiver operating characteristic) curve is displayed in Figure 2.

\section{Discussion}

This study applied a drop count methodology to adjust the claims-based days supply variable for topical IOP-lowering glaucoma medications in order to develop and validate a claims-based predictive model for estimating the probability of being nonadherent $(\mathrm{PDC}<0.80)$. The medical and pharmacy variables evaluated for the predictive model included those that are readily available in administrative claims databases and have been shown to influence medication adherence in other contexts. ${ }^{14,29}$ Common and relevant variables were extracted from the claims database and included as variables in the predictive model. The predictive model resulted in an AUC of at least $0.70 . .^{30}$ 


\section{FIGURE 2 ROC Curve, Model Develpment}

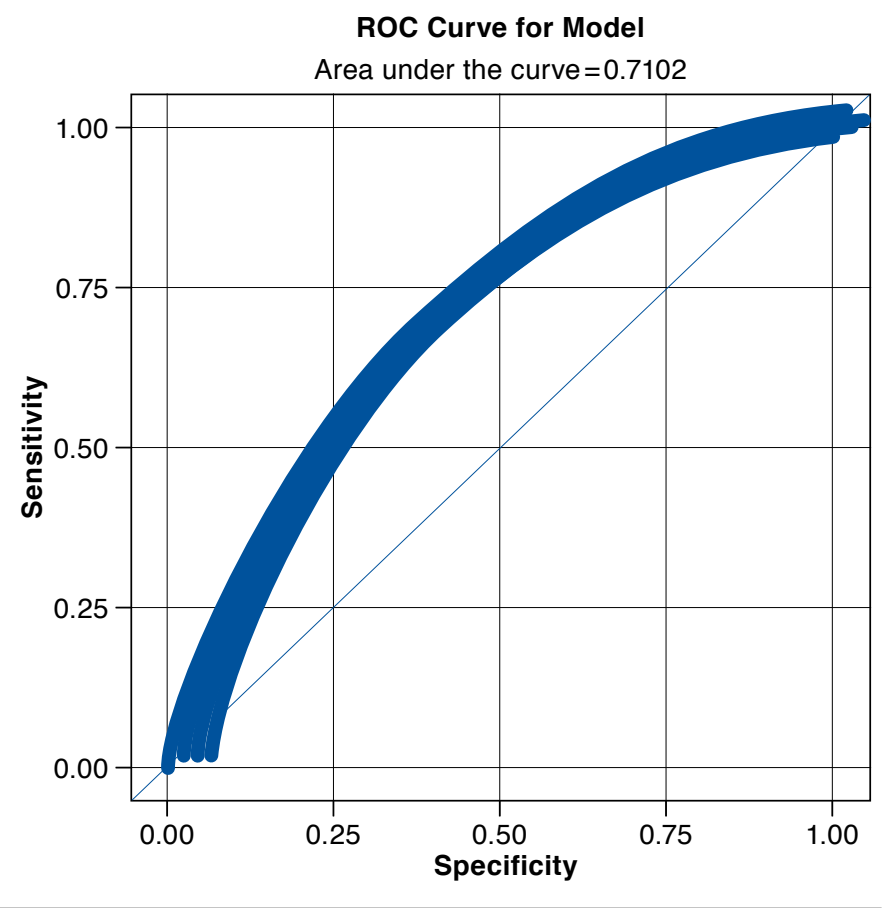

ROC $=$ receiver operating characteristic.

Patients who were likely to be nonadherent had their first IOP-lowering prescription filled via mail order, were new users, were male, and had higher medical costs. The finding that mail order as a predictor is somewhat counterintuitive. However, it is important to note that a patient was identified as "mail order" if the first IOP prescription filled for an IOP medication was in the 12 -month identification period. This variable represents a snapshot in time-it does not define the use of mail order or retail for the entire 12-month post-index period nor does it identify patients exclusively using mail order as the sole distribution channel for IOP medications. Patients who were more likely to be adherent were older, had glaucoma surgery, were diagnosed by an ophthalmologist, had higher pharmacy costs, resided in the South, and received a low-income subsidy.

Based on the model replication in the development and validation samples, the predictive model appears to be robust in this MAPD population. This predictive model was developed using Humana's administrative claims database. There are limitations, however, in the database's ability to generalize to all MAPD plans or members on fee-for-service Medicare. The expectation is that the model is generalizable to similar MAPD plans available in the South and Midwest regions, since the majority of Humana's plans are offered in these areas. Given that this predictive model was constructed using vari- ables generally available in U.S. administrative claims data, it could potentially be replicated by other health plans for use in predicting nonadherence to topical IOP-lowering medications among MAPD plan patients, in order to target interventions intended to improve glaucoma medication adherence. The ease of replication and interpretability of this model also may be leveraged to explore relationships in other administrative claims datasets.

Finally, an additional model was created using only variables available in pharmacy claims data, which resulted in a similar number of variables and AUC as the MAPD model. The mean adherence for MAPD patients taking IOP-lowering topical medications in this study was $\mathrm{PDC}=0.72$, similar to other studies that examined mean adherence rates for IOPlowering medications. ${ }^{11,31}$ Likewise, some of the predictors have been seen in past research such as previous diagnoses of open-angle glaucoma as a predictor of adherence and new users having lower adherence. ${ }^{11,32}$ However, while age and sex were found to be significant predictors in the current study, there have been conflicting findings in past research. ${ }^{11,14}$ This may be a result of the differences in member populations examined; for example, the Gurwitz et al. (1993) study examined a New Jersey Medicaid population and selected elderly patients aged $>65$ years. ${ }^{11}$ While the current study of MAPD patients did not find Medicaid as a significant predictor, Gurwitz et al. found that the low-income subsidy component was a significant predictor of adherence. Low-income subsidy status refers to Medicare beneficiaries with income below $150 \%$ of poverty level and with limited resources and who are eligible for additional premium and cost-share assistance for prescription drugs under the MAPD program.

The predictive model generated through the current study can be used to identify patients who are likely to be nonadherent to topical IOP-lowering glaucoma medications. Future research can replicate this model using other administrative claims databases in order to identify and prioritize patients that are at risk for nonadherence. Flagging these patients will allow health plan administrators to identify appropriate patients for targeted adherence interventions.

\section{Limitations}

This study used data from the Humana administrative claims database only, so the results may not be generalizable; however, Humana is a large national health plan with members residing throughout the United States in a broad array of geographic regions. Moreover, the variables included in the final predictive model are available in other U.S. administrative claims databases. This study examined only MAPD plan members, since glaucoma is more prevalent in the elderly. ${ }^{2}$ The methodology to calculate days supply using the drop count approach allowed for 
the accounting of possible overfill of the eye drop bottles; however, the drop count studies provided an external source of data that needed to be integrated with the dataset used for analysis.

Additionally, limitations common to studies using administrative claims data apply to this study. ${ }^{33-36}$ These limitations include lack of certain information in the database and errors or omissions in claims coding. Administration of sample medications or medications acquired without using the pharmacy benefit could limit the detection of medication use. Unmeasured confounders may limit the findings. Limitations exist around estimating adherence using administrative claims data; for example, proper administration and placement of drops in the eye cannot be ensured, and many patients may use more than 1 drop per eye. The goal of this study was to use administrative claims data to source the variables for the predictive model. The mobility and clinical factors that may be captured in a patient's medical chart may provide additional information in understanding adherence to ophthalmic medications.

\section{Conclusions}

The results of this study show that nonadherence to topical IOP-lowering medication can be predicted with 10 commonly available demographic and administrative claims-based variables. Based on the model replication in development and validation samples, the predictive model appears to be robust in this MAPD population. Given that this predictive model was constructed using variables generally available in U.S. administrative claims data, it could potentially be replicated by other health plans for use in predicting nonadherence to topical IOPlowering medications among MAPD plan members. Results from the implementation of this model may be used to target interventions intended to improve medication adherence.

Authors

RICHARD SHEER, BA; SUVAPUN BUNNIRAN, PhD; and CLAUDIA URIBE, MD, MHA, PhD, Comprehensive Health Insights, Humana, Louisville, Kentucky. RICHARD G. FISCELLA, PharmD, MPH, Health Economics and Outcomes Research Medical Science Liaison; VAISHALI D. PATEL, PharmD, MS, Global Health Economics and Outcomes Research; and HITESH S. CHANDWANI, MBBS, PhD, Global Health Economics and Outcomes Research, Allergan, Irvine, California.

AUTHOR CORRESPONDENCE: Suvapun Bunniran, PhD, Principal Researcher, Comprehensive Health Insights, Humana, 515 W. Market St., 7th Fl., Louisville, KY 40202. Tel.: 502.476.0614; Fax: 502.508.9456; E-mail: sbunniran@humana.com.

\section{DISCLOSURES}

Funding for this study was contributed by Allergan. Comprehensive Health Insights was contracted by Allergan to conduct this study. Sheer, Bunniran, and Uribe are employed by Comprehensive Health Insights/Humana and own stock in Humana. Fiscella, Chandwani, and Patel are employed by Allergan.

Study concept and design were contributed by Sheer, Fiscella, and Patel, along with Bunniran and Uribe. Sheer and Bunniran took the lead in data collection, and data interpretation was performed by Bunniran and Uribe, along with the other authors. The manuscript was written and revised by Sheer, Bunniran, Chandwani, and Uribe, with assistance from Fiscella and Patel.

\section{REFERENCES}

1. Reardon G, Kotak S, Schwartz G. Objective assessment of compliance and persistence among patients treated for glaucoma and ocular hypertension: a systematic review. Patient Prefer Adherence. 2011;5:441-63.

2. Prevent Blindness America. Vision problems in the U.S.: prevalence of adult vision impairment and age-related eye disease in America. Glaucoma prevalence by age. 2012. Available at: http://www.visionproblemsus.org/glaucoma/glaucoma-age.html. Accessed June 6, 2016

3. Centers for Disease Control and Prevention. Improving the nation's vision health: a coordinated public health approach. Available at: http://www.cdc. gov/visionhealth/pdf/improving_nations_vision_health.pdf. Accessed May 21, 2016

4. National Center for Chronic Disease Prevention and Health Promotion, The Division of Diabetes Translation. The state of vision, aging, and public health in America. Centers for Disease Control and Prevention. 2011. Available at: http://www.cdc.gov/visionhealth/pdf/vision_brief.pdf. Accessed May 21, 2016.

5. Klein R, Klein B. The prevalence of age-related eye diseases and visual impairment in aging: current estimates. Invest Ophthalmol Vis Sci. 2013;54(14):ORSF5-ORSF13.

6. Sleath B, Blalock S, Covert D, et al. The relationship between glaucoma medication adherence, eye drop technique, and visual field defect severity. Ophthalmology. 2011;118(12):2398-402.

7. Stryker J, Beck A, Primo S, et al. An exploratory study of factors influencing glaucoma treatment adherence. J Glaucoma. 2010;19(1):66-72.

8. Vermeire E, Hearnshaw H, Van Royen P, Denekens J. Patient adherence to treatment: three decades of research. A comprehensive review. J Clin Pharm Ther. 2001;26(5)331-42.

9. Christensen K, Doblhammer G, Rau R, Vaupel J. Ageing populations: the challenges ahead. Lancet. 2009;374(9696):1196-2008.

10. Centers for Medicare \& Medicaid Services. Chronic conditions among Medicare beneficiaries, chartbook: 2012 edition. Baltimore, MD. 2012. Available at: https://www.cms.gov/Research-Statistics-Data-and-Systems/ Statistics-Trends-and-Reports/Chronic-Conditions/Downloads/ 2012Chartbook.pdf. Accessed May 21, 2016.

11. Gurwitz J, Glynn R, Monane M, et al. Treatment for glaucoma: adherence by the elderly. Am J Public Health. 1993;83(5):711-16.

12. Gurwitz J, Yeomans S, Glynn R, Lewis B, Levin R, Avorn J. Patient noncompliance in the managed care setting. The case of medical therapy for glaucoma. Med Care. 1998;36(3):357-69.

13. Boland M, Chang D, Frazier T, Plyler R, Friedman D. Electronic monitoring to assess adherence with once-daily glaucoma medications and risk factors for nonadherence: the Automated Dosing Reminder Study. JAMA Ophthalmol. 2014;132(7):838-44

14. Chang D, Friedman D, Frazier T, Pyler B, Boland M. Development and validation of a predictive model for nonadherence with once-daily glaucoma medications. Ophthalmology. 2013;120(7):1396-402.

15. Olthoff C, Schouten J, van de Borne B, Webers C. Noncompliance with ocular hypotensive treatment in patients with glaucoma or ocular hypertension an evidence-based review. Ophthalmology. 2005;112(6):953-61. 
16. Djafari F, Lesk M, Harasymowycz P, Desjardins D, Lachaine J. Determinants of adherence to glaucoma medical therapy in a long-term patient population. J Glaucoma. 2009;18(3):238-43.

17. Sloan K, Sales A, Liu C, et al. Construction and characteristics of the RxRisk-V: a VA-adapted pharmacy-based case-mix instrument. Med Care. 2003;41(6):761-74.

18. Sales AE, Liu CF, Sloan KL, et al. Predicting costs of care using a pharmacy-based measure risk adjustment in a veteran population. Med Care. 2003;41(6):753-60.

19. Farley J, Harley C, Devine J. A comparison of comorbidity measurements to predict healthcare expenditures. Am J Manag Care. 2006;12(2):110-19.

20. Fishman P, Goodman M, Hornbrook M, Meenan R, Bachman D, O'Keeffe RM. Risk adjustment using automated ambulatory pharmacy data: the RxRisk model. Med Care. 2003;41(1):84-99.

21. Briggs A, Nixon R, Dixon S, Thompson S. Parametric modelling of cost data: some simulation evidence. Health Econ. 2005;14(4):421-28.

22. Austin P, Ghali W, Tu J. A comparison of several regression models for analysing cost of CABG surgery. Stat Med. 2003;22(17):2799-815.

23. Grymonpre R, Didur C, Montgomery P, Sitar D. Pill count, self-report, and pharmacy claims data to measure medication adherence in the elderly. Ann Pharmacother. 1998;32(7-8):749-54.

24. Campbell J, Schwartz G, LaBounty B, Kowalski J, Patel V. Patient adherence and persistence with topical ocular hypotensive therapy in real world practice: a comparison of bimatoprost $0.01 \%$ and travoprost Z $0.004 \%$ ophthalmic solutions. Clin Ophthalmol. 2014;8:927-35.

25. Rylander N, Vold S. Cost analysis of glaucoma medications. Am J Ophthalmol. 2008;145(1):106-13.

26. Nau D. Proportion of days covered (PDC) as a preferred method of measuring medication adherence. Pharmacy Quality Alliance. Available at: http://ep.yimg.com/ty/cdn/epill/pdcmpr.pdf. Accessed May 21, 2016.
27. Yeaw J, Benner JS, Walt JG, Sian S, Smith DB. Comparing adherence and persistence across 6 chronic medication classes. J Manag Care Pharm. 2009;15(9):724-36. Available at: http://www.amcp.org/data/jmcp/728-740.pdf.

28. Bryant F, Yarnold P. Reading and Understanding Multivariate Statistics. Vol. 9. Washington, DC: American Psychological Association; 1995

29. Friedman DS, Quigley HA, Gelb L, et al. Using pharmacy claims data to study adherence to glaucoma medications: methodology and findings of the Glaucoma Adherence and Persistency Study (GAPS). Invest Ophthalmol Vis Sci. 2007:48(11):5052-57.

30. Hanley J, McNeil B. The meaning and use of the area under a receiver operating characteristic (ROC) curve. Radiology. 1982;143(1):29-36.

31. Wilensky J, Fiscella RG, Carlson AM, Morris LS, Walt J. Measurement of persistence and adherence to regimens of IOP-lowering glaucoma medications using pharmacy claims data. Am J Ophthalmol. 2006;141(1 Suppl):S28-33.

32. Nordstrom BL, Friedman DS, Mozaffari E, Quigley HA, Walker AM. Persistence and adherence with topical glaucoma therapy. Am J Ophthalmol. 2005;140(4):598-606.

33. Grimes D. Epidemiologic research using administrative databases: garbage in, garbage out. Obstet Gynecol. 2010;116(5):1018-19.

34. Hennessy S. Use of health care databases in pharmacoepidemiology. Basic Clin Pharmacol Toxicol. 2006;98(3):311-13.

35. Hersh WR, Weiner MG, Embi PJ, et al. Caveats for the use of operational electronic health record data in comparative effectiveness research. Med Care. 2013;51(8 Suppl 3):S30-37.

36. Schneeweiss S, Avorn J. A review of uses of health care utilization databases for epidemiologic research on therapeutics. J Clin Epidemiol. 2005;58(4):323-37. 


\begin{tabular}{|c|c|}
\hline APPENDIX Input Mod & el Variables \\
\hline Variable & Values \\
\hline Age & Integer (65-89) \\
\hline Patient gender & Male, female \\
\hline Race & White, black, Hispanic, other \\
\hline Region & Northeast, Midwest, South, West \\
\hline Plan type & $\mathrm{HMO}, \mathrm{PPO}$, other \\
\hline LIS & $\mathrm{Y} / \mathrm{N}$ \\
\hline Rx-Risk-V & Integer (0-33) \\
\hline Hypertension & $\mathrm{Y} / \mathrm{N}$ \\
\hline Hyperlipidemia & $\mathrm{Y} / \mathrm{N}$ \\
\hline Diabetes & $\mathrm{Y} / \mathrm{N}$ \\
\hline Congestive heart failure & $\mathrm{Y} / \mathrm{N}$ \\
\hline Joint disorders & Y/N \\
\hline Muscle weakness/movement disorders & Y/N \\
\hline Mental disorders & $\mathrm{Y} / \mathrm{N}$ \\
\hline Glaucoma & $\mathrm{Y} / \mathrm{N}$ \\
\hline Glaucoma surgery & $\mathrm{Y} / \mathrm{N}$ \\
\hline Glaucoma-related eye exam & $\mathrm{Y} / \mathrm{N}$ \\
\hline OAG diagnosed by ophthalmologist & $\mathrm{Y} / \mathrm{N}$ \\
\hline Number of pharmacies used & Integer \\
\hline Number of physicians seen & Integer \\
\hline New user & $\mathrm{Y} / \mathrm{N}(\mathrm{N}=$ continuing user $)$ \\
\hline Mail order ${ }^{\mathrm{a}}$ & $\mathrm{Y} / \mathrm{N}(\mathrm{N}=$ retail $)$ \\
\hline Prescriber gender & Male, female \\
\hline Prescriber specialty ${ }^{\mathrm{a}}$ & Ophthalmologist, optometrist, other \\
\hline Formulary tier & 1,2, other \\
\hline Prescription source ${ }^{\mathrm{a}}$ & Written, fax, phone, electronic, other \\
\hline Pre-index medical costs & Continuous (log adjusted) \\
\hline Pre-index pharmacy costs & Continuous (log adjusted) \\
\hline \multicolumn{2}{|c|}{$\begin{array}{l}\text { Note: Bold items retained in final model. } \\
\text { aBased on index IOP-lowering medication prescription. } \\
\text { HMO=health maintenance organization; IOP=intraocular pressure; } \\
\text { LIS=low-income subsidy; OAG=open-angle glaucoma; } P P O=\text { preferred provider } \\
\text { organization; Y/N=yes/no. }\end{array}$} \\
\hline
\end{tabular}

